\title{
A INFLUÊNCIA DO MARKETING VERDE NOS HÁBITOS DE CONSUMO DOS JOVENS UNIVERSITÁRIOS DOS CURSOS DE ADMINISTRAÇÃO: ESTUDO EM INSTITUIÇÕES DE ENSINO SUPERIOR (IES)
}

\author{
Rejane Alexandrina Domingues Pereira do Prado \\ Doutoranda em Administração pela Universidade Nove de Julho - UNINOVE \\ Professora pela Universidade Federal de Uberlândia - UFU \\ E-mail: rejane@pontal.ufu.br (Brasil)
}

\section{Marli Auxiliadora da Silva}

Doutoranda em Educação pela Universidade Federal de Uberlândia - UFU

Professora pela Universidade Federal de Uberlândia - UFU

E-mail: marli@pontal.ufu.br (Brasil)

\section{Maíra Cinquini Junqueira}

Graduanda em Administração Universidade Federal de Uberlândia - UFU

E-mail: maira_ccij@yahoo.com.br (Brasil)

\author{
Lia Noronha Nunes Almeida \\ Graduanda em Administração Universidade Federal de Uberlândia - UFU \\ E-mail : lia-noronha@hotmail.com (Brasil)
}

\section{RESUMO}

Impactos negativos decorrentes de atividades mercadológicas e industriais sustentadoras das sociedades capitalistas estão explícitos no meio ambiente trazendo consequências como a poluição, acúmulo de resíduos e destruição da fauna e flora, entre outras. Decorrente dessa constatação, um número cada vez maior de indivíduos percebe que é parte ativa do processo de destruição do meio ambiente, e que seus atos tanto podem contribuir para agravar como para melhorar tal situação. Considerando essa nova realidade, o objetivo deste estudo consiste na análise da influência do marketing verde nos hábitos de consumo dos estudantes de duas IES, no interior de Minas Gerais, para investigar se eles reconhecem a importância dessa prática e, se, enquanto futuros administradores buscariam incentivá-la em suas empresas. Foi feita uma pesquisa bibliográfica, para conceituar os temas: marketing verde, comportamento do consumidor e consumo consciente. $\mathrm{O}$ instrumento de pesquisa foi o questionário. Os dados coletados foram analisados usando-se o software estatístico SPSS. O estudo possibilitou inferir que há uma enorme distância entre o que os jovens pensam e suas verdadeiras ações em relação às questões ambientais. Apesar reconhecerem a importância do marketing verde nas empresas, a maioria dos entrevistados afirma não ser influenciado por essa prática, de forma que não possuem hábitos de consumo consciente.

Palavras-Chave: Marketing; Marketing verde; Hábitos de consumo; Graduandos em administração. 


\section{INTRODUÇÃ̃o}

Vive-se atualmente um período no qual estão explícitos os impactos negativos que as atividades mercadológicas e industriais, que sustentam as sociedades capitalistas, exercem no meio ambiente. Os impactos provocados por essas atividades têm como consequências a poluição, o desmatamento, além do acúmulo de resíduos, entre outros, e são tão graves que já afetam a qualidade de vida de muitas pessoas e comprometem a sobrevivência das gerações futuras e de toda a sociedade.

As empresas, que são parte desta sociedade, devem cumprir metas cada vez maiores, relativas a desempenho ambientalmente sustentável, respeitar leis mais rígidas e ter responsabilidades sociais e ambientais mais transparentes sem, contudo, deixar de priorizar e garantir a obtenção de lucros em suas atividades (Donaire, 1994; Pombo \& Magrini, 2008).

Diante desse cenário, cada vez mais indivíduos e gestores empresariais estão se percebendo como parte ativa do processo de destruição do meio ambiente, e que seus atos tanto podem contribuir para agravar essa situação como podem contribuir positivamente para que mudanças aconteçam. Um exemplo de mudanças no comportamento e hábito de consumo dos cidadãos tem sido expresso através do consumo consciente, por meio do qual os consumidores dão preferência a produtos que sejam ecologicamente corretos.

Por outro lado, as empresas também têm sido motivadas e, de certa forma, obrigadas a produzir produtos "verdes". Tal fato decorre da necessidade de uma resposta mercadológica das empresas às pressões que grupos de consumidores mais preocupados com as questões ambientais começaram a exercer (Mintu-Wimsatt \& Bradford, 1995).

As empresas estão em uma fase de integração do controle ambiental na gestão administrativa e, nesta fase, D’Avignon (1996) destaca que os parâmetros relacionados ao meio ambiente passam a ser levados em conta no planejamento estratégico, no processo produtivo, na distribuição e disposição final do produto, resultando, por conseguinte, em aumento da importância do profissional da administração no gerenciamento dessa nova exigência do mercado.

Entendendo a relevância desse tema, o estudo se propôs a analisar a questão do consumo consciente, mas de uma forma mais específica, por meio da análise de um nicho particular. Para tanto, questionou-se a percepção dos jovens estudantes de administração, no sentido de verificação do comportamento relativo a questões ambientais desse público, tanto como consumidores quanto

REMark - Revista Brasileira de Marketing, São Paulo, v. 10, n. 2, p 126-145, mai./ago. 2011. 
com relação às expectativas de sua vida profissional, enquanto futuros administradores. Assim, o objetivo do presente estudo consistiu na análise da influência do marketing verde nos hábitos de consumo dos estudantes de duas instituições de ensino superior (IES), no interior de Minas Gerais, para identificar se eles reconhecem a importância dessa prática e, se, como futuros administradores, buscariam incentivá-las em suas empresas.

Este artigo está estruturado em seis seções. Inicialmente, tem-se esta parte introdutória e, na sequência, a revisão bibliográfica. Na terceira seção, encontram-se os procedimentos metodológicos da pesquisa. Posteriormente, apresenta-se a análise e discussão dos resultados, seguida das considerações finais e referências.

\section{REVISÃO BIBLIOGRÁFICA}

A seguir são discutidos conceitos sobre marketing verde, produto ecologicamente correto, comportamento do consumidor e do profissional administrador e sua responsabilidade com o marketing verde.

\subsection{O MARKETING VERDE}

O marketing possui a função de identificar as necessidades e os desejos do consumidor, determinar os mercados-alvo nos quais a organização possa atuar e desenvolver o planejamento de produtos, serviços e programas mais adequados a esses mercados (Kotler, 1999). Dentre as classificações de marketing tem-se o Marketing Verde ou Ambiental que, conforme Polonski (1994), consiste em todas as atividades designadas para gerar e facilitar qualquer troca com o objetivo de satisfazer os desejos ou necessidades humanas, desde que a satisfação dessas necessidades e desejos ocorra com o mínimo de impacto prejudicial sobre o meio ambiente. Peattie (1995) definiu o Marketing Verde como o processo de gestão holística responsável por identificar, antecipar e satisfazer as exigências dos clientes e da sociedade de uma forma rentável e sustentável.

Barbieri (2007, p. 25) afirma que a Gestão Ambiental deve ser entendida como: as diretrizes e as atividades administrativas e operacionais, tais como planejamento, direção, controle, alocação de recursos e outras realizadas com o objetivo de obter efeitos positivos sobre o meio ambiente,

REMark - Revista Brasileira de Marketing, São Paulo, v. 10, n. 2, p 126-145, mai./ago. 2011. 
quer reduzindo ou eliminando os danos ou problemas causados pelas ações humanas, quer evitando que eles surjam.

Roxo (1996, p. 14) cita que “[...] as questões de meio ambiente ganharam considerável relevância, a ponto de se tornarem um fator de competição entre empresas e países, assumindo assim caráter altamente estratégico". Visto as discussões sobre sustentabilidade, dadas as questões ambientais, Charter (1992) assegura que a sustentabilidade deve ser a marca registrada da filosofia do Marketing Verde.

Seja por questão de pressão dos cidadãos, ONGs e governo, facilidade em obter recursos, redução de custos, busca por vantagem competitiva, seja para promover uma boa imagem da marca perante os consumidores, o fato é que as organizações estão investindo cada vez mais no desenvolvimento sustentável. Isso significa que as empresas, no desenvolvimento de ações e estratégias para atingir seus objetivos, levam em consideração questões éticas e sociais relevantes, como a preocupação em preservar o meio ambiente. A “onda" verde, segundo Haour (1999), veio para ficar e cabe às empresas se adaptar e integrar as preocupações ambientais em cada aspecto da administração.

A organização não governamental brasileira WWF Brasil afirma que o consumidor é cada vez mais consciente do peso ecológico e social de suas próprias escolhas e, desse modo, para a empresa garantir a satisfação dos consumidores terá, cada vez mais, que fornecer respostas coerentes com estes assuntos, reconhecendo a crescente sensibilidade do mercado às temáticas como a sustentabilidade, empenhando-se a atingir resultados positivos a favor do ambiente. Empresas que queiram manter a competitividade a longo prazo devem, portanto, responder às expectativas dos cidadãos-consumidores, valorizando o comportamento responsável (WWF Brasil, 2010).

Entende-se por conscientização ambiental a mudança de comportamento, tanto de atitudes quanto de aspectos da vida, dos indivíduos e da sociedade em relação ao meio ambiente. A conscientização da sociedade quanto às questões ambientais é fator imprescindível para a sensibilização e para o comportamento ecológico fazendo com que as pessoas prefiram produtos ecologicamente corretos tornando-se, assim, consumidores ecológicos (Butzke, Pereira, \& Noebauer, 2002; García, Aldamiz-Echevarría, Durana, Abando, \& Molina, 2003).

Essa exigência de mudança e adequação no comportamento das empresas resulta em desenvolvimento sustentável, que é definido como aquele desenvolvimento que atende às

REMark - Revista Brasileira de Marketing, São Paulo, v. 10, n. 2, p 126-145, mai./ago. 2011. 
necessidades do presente sem comprometer a possibilidade de as gerações futuras atenderem às suas próprias necessidades (Eco \& Ação, 2010).

Nesse processo o marketing verde ganha importância, como uma forma das empresas estimularem e influenciarem os consumidores a comprarem produtos que sejam ecologicamente corretos. Estabelece-se, portanto, uma importante ligação entre empresas e cidadãos, na qual as empresas ficam responsáveis por fornecer aos cidadãos uma alternativa ecologicamente correta de consumo, e estes a aderirem a esta causa, incentivando cada vez mais esse movimento "verde".

Em uma definição mais objetiva e clara, dada por Ferrell e Pride (2001), marketing verde se refere, especificamente, ao desenvolvimento, aperfeiçoamento, promoção e distribuição de produtos que não agridam o ambiente natural. De acordo com esses conceitos, pode-se afirmar que o Marketing Verde, também conhecido por Marketing Ambiental, Ecologicamente Correto ou Ecomarketing, incorpora em todas as atividades a cargo do marketing a preocupação ambiental, visando atender a uma nova e crescente demanda da população por produtos ecologicamente corretos.

Nesse contexto, o Marketing Verde deve considerar atividades como planejamento e desenvolvimento de novos produtos, alterações no processo de produção, logística, embalagem, preços, promoção e distribuição (Welford, 1995; Wasik, 1996; Ottman, 1998; Peattie, 1999; Polonsky \& Rosenberger, 2001; Chamorro \& Bañegil, 2006).

\subsubsection{PRODUTO ECOLOGICAMENTE CORRETO}

Antes de discutir o termo "produto ecologicamente correto" faz-se necessário entender o conceito de produto em si. Gobe, Moreira, Perez, Carramenha e Pasquale (2004) e Kotler e Keller (2006) conceituam produto como o conjunto de atributos tangíveis e intangíveis que proporcionam valor, benefícios reais ou percebidos, cuja finalidade é satisfazer as necessidades e os desejos do consumidor. Produto ecologicamente correto incorpora, também, a variável ambiental, a qual deve estar presente nas decisões do produto (Motta, 2007).

A oferta de produtos ecologicamente corretos começou a ocorrer com maior intensidade a partir da década de 90 (Ottman, 1994), sendo esse aumento resultante da importância dada àquelas empresas que se mostram "amigas da natureza" visto que a sociedade tem exigido tal comportamento (Silva, 2001; Donaire, 1999) e, para demonstrar esta "amizade", verifica-se que a

REMark - Revista Brasileira de Marketing, São Paulo, v. 10, n. 2, p 126-145, mai./ago. 2011. 
partir desse período as empresas começaram a lançar produtos ecologicamente corretos (Menon, Anil, Menon, Ajay, Chowdhury, \& Jankovich, 1999; Tse \& Yim, 2002).

O ideal seria que todos os consumidores e todas as empresas tivessem a preocupação ambiental, todavia, não é isso que é percebido. Motta e Rossi (2003) afirmam que, no Brasil, a necessidade de preservar o meio ambiente não está presente na maioria das decisões de consumo, e mesmo quando está, perde em importância para as vantagens e benefícios que a utilização do produto possa proporcionar. A análise das decisões de consumo consciente depende da análise do comportamento dos consumidores.

\subsection{COMPORTAMENTO DO CONSUMIDOR}

Os consumidores no seu processo de decisão de compra possuem comportamentos distintos. Uma vez que o objetivo do marketing está em atender e satisfazer às necessidades e aos desejos dos consumidores, torna-se essencial conhecer o comportamento de compra destes. É preciso que as empresas conheçam seus consumidores para que possam perceber e reagir às mudanças nos hábitos de consumo destes, e assim manter sua competitividade no mercado (Kotler \& Keller, 2006).

Limeira (2008) destaca que a teoria tradicional do consumidor, baseada em conceitos da perspectiva comportamentalista da psicologia, define o comportamento do consumidor como um conjunto de reações ou respostas dos indivíduos a determinados estímulos, os quais decorrem de fatores pessoais, ambientais, situacionais e de marketing. Mowen e Minor (2003) complementam que o comportamento do consumidor é definido como o estudo das unidades compradoras e dos processos de troca envolvidos na aquisição, no consumo e na disposição de mercadorias, serviços, experiências e ideias.

A nova tendência no comportamento de compra dos consumidores revela que as pessoas estão tendo consciência de que suas atitudes têm reflexos nas questões ambientais e que, portanto, possuem responsabilidades em buscar alternativas para minimizar os impactos ecológicos. De acordo com essa nova tendência, verifica-se uma mudança nos hábitos de compra dos consumidores que vêm aderindo ao consumo consciente e preferem produtos que possuam alguma identificação de que não agridem, ou agridem minimamente o meio ambiente. O Instituto Akatu (2009) afirma que consumo consciente é um consumo com consciência de seu impacto e voltado à

REMark - Revista Brasileira de Marketing, São Paulo, v. 10, n. 2, p 126-145, mai./ago. 2011. 
sustentabilidade, ou seja, é ter consciência que escolhas de consumo refletirão não só em nossas vidas, mas também na vida do planeta.

Na concepção de Stone, Barnes e Montgomery (1995), o consumo consciente, ou seja, aquele que envolve responsabilidade ecológica reflete conscientização, valores pessoais, além do desejo genuíno de agir de acordo com esse objetivo. Smith e Haugtvedt (1995) e Waissman (2001) asseguram que, apesar de a sociedade afirmar que está mudando suas atitudes em relação às questões ambientais, na prática ainda há dissonância entre a tendência da intenção e a realidade dos fatos diante do comportamento. Tal afirmativa permite inferir que, embora os consumidores se digam mais conscientes, ainda são identificadas atitudes contrárias às afirmações.

Starke (1991) reforça que a mudança de comportamento dos consumidores tem atraído a atenção de um número crescente de empresas que estão descobrindo as vantagens estratégicas do marketing ecológico. Ottman (1994) corrobora, afirmando que uma manifestação dessa mudança é o número crescente de consumidores que tomam decisão de marca com base em registro de realizações de fabricante quanto a critérios ambientais e sociais, os quais em seus momentos de decisão de compra questionam se o produto é realmente "verde".

O papel do profissional da administração, responsável pela gestão das empresas, torna-se, portanto, imprescindível para acelerar essas mudanças do consumo de produtos tradicionais para o consumo ampliado de produtos "verdes".

\subsection{O PROFISSIONAL ADMINISTRADOR E SUA RESPONSABILIDADE COM O MARKETING VERDE}

Nos últimos anos têm sido introduzidas na grade curricular dos cursos de Administração disciplinas relacionadas à Gestão Ambiental, em função das mudanças e exigências ocorridas no mercado, em relação à variável ambiental, além da percepção, por parte dos educadores, da necessidade de se discutir questões relativas à responsabilidade socioambiental das empresas e dos benefícios, tanto fiscais quanto mercadológicos, de sua implementação. Ademais, a promulgação, em 7 de abril de 1999, pela Presidência da República da Política Nacional de Educação Ambiental (PNEA), por meio da Lei $n^{\circ}$ 9.795, evidencia e ratifica a importância da incorporação da Educação Ambiental à matriz curricular dos cursos de gestão, conforme disposto no artigo $8^{\circ}$, parágrafos $2^{\underline{0}}$ e $3^{\circ}$, que cita que a lei visa:

REMark - Revista Brasileira de Marketing, São Paulo, v. 10, n. 2, p 126-145, mai./ago. 2011. 
[...] A incorporação da dimensão ambiental na formação, especialização e atualização dos educadores de todos os níveis e modalidades de ensino, assim como de todos os profissionais de todas as áreas; preparação de profissionais orientados para as atividades de gestão ambiental; a busca de alternativas curriculares e metodológicas de capacitação na área ambiental (Brasil, 1999).

Nessa linha, percebe-se a preocupação do governo com a formação de educadores para a disseminação do conhecimento sobre as questões ambientais necessárias ao desenvolvimento sustentável do país. Cascino (2000) destaca que a construção de uma educação, passando pelas graves e urgentes questões ambientais, é tarefa inadiável e que compete aos educadores não permitir que a mediocridade dos mercados impeça a realização dessa tarefa.

D. D. M. Ferreira e L. F. Ferreira (2008) citam que as instituições de ensino superior têm feito essas mudanças curriculares por acreditarem que com essa atitude o futuro profissional desenvolverá os princípios e atividades da organização obedecendo a uma conduta minimamente sustentável. Apesar do esforço de algumas instituições, verifica-se que muitas ainda não tiveram essa preocupação. Ribeiro e Miranda (2011) afirmam que, atualmente, faltam à maioria dos gestores organizacionais conhecimentos dessa temática, além de verificar-se baixo grau de conscientização crítica nas questões ambientais, visto esses não terem recebido, desde sua formação no ensino fundamental, as informações que lhes dariam, no mínimo, um aporte teórico para repensar seus hábitos, valores e ações.

Dias (2006) afirma que o papel da educação ambiental, no contexto atual, torna-se mais urgente e é necessário oferecer mais informação, visto que a educação ainda treina o (a) estudante para ignorar as consequências ecológicas de seus atos. Outro fator a se considerar é que mesmo em instituições que possuem a preocupação e oferecem a disciplina, os graduandos, muitas vezes, não entendem essa necessidade, ou entendem, mas não aderem à questão ambiental.

Sobre o assunto, Barbieri (2007, p. 77) destaca que "a meta da educação ambiental é desenvolver uma população consciente e preocupada com o meio ambiente para atuar individual e coletivamente na busca de soluções para os problemas atuais e para a prevenção de novos problemas".

As discussões sobre a temática deixam claro que é necessário ao administrador conhecer temas que, além de relevantes à sua formação, o auxiliem na realização de suas atividades no mercado empresarial. Dentre esses temas citam-se a educação ambiental, gestão ambiental, responsabilidade social e sustentabilidade, as quais possibilitarão ao administrador tornar-se um

REMark - Revista Brasileira de Marketing, São Paulo, v. 10, n. 2, p 126-145, mai./ago. 2011. 
agente ativo para ações que conduzam ao crescimento e melhoria das organizações. Ribeiro e Miranda (2011, p. 213) afirmam que:

"Formar administradores comprometidos com a questão ambiental é de extrema relevância, pois as organizações que têm, em seu comando, executivos preocupados com a proteção e preservação do meio ambiente ocuparão um lugar de destaque no mercado, além de estarem ratificando a credibilidade em relação ao seu público consumidor."

Apesar de haver uma clara percepção da urgência de implantar disciplinas na área de gestão ambiental nos cursos de administração para formação de gestores mais capacitados a lidar com a questão, muitas IES não aderem a essa proposição, visto que a exigência ainda não é contemplada pela Câmara de Educação Superior do Conselho Nacional de Educação em relação aos cursos de Administração, não sendo, portanto, explícitas tais disciplinas nas Diretrizes Curriculares Nacionais do Curso de Graduação em Administração, a fim de serem oferecidas pelas IES e, por isso, alguns coordenadores de curso aderem a essa prática, enquanto outros não (Ribeiro \& Miranda, 2011).

\section{PROCEDIMENTOS METODOLÓGICOS}

Para o desenvolvimento deste estudo procedeu-se a pesquisa exploratória e a de campo. A pesquisa exploratória permite ao pesquisador obter um maior aprofundamento sobre o tema pesquisado ou problema de pesquisa analisado (Mattar, 1996) e foi feita com o intuito de explorar conceitos relativos a temáticas como marketing, marketing verde, produto ecologicamente correto, além de comportamento do consumidor, consumo consciente e o profissional administrador e sua responsabilidade com o marketing verde. Ressalta-se que esses conceitos embasaram a análise dos resultados obtidos por meio da pesquisa de campo.

A pesquisa de campo, efetuada mediante a aplicação de questionário, composto de perguntas de múltipla escolha, perguntas dicotômicas (sim e não) e perguntas de escala de importância objetivou a sondagem da percepção dos jovens universitários sobre a temática e a posterior análise da influência dos apelos do marketing verde exercida pelas empresas que adotam procedimentos ambientalmente corretos sobre o comportamento dos respondentes. A coleta de dados buscou conhecer, ainda, se os jovens reconhecem a importância dessa prática, e se, como futuros administradores, buscariam incentivá-las em suas empresas.

REMark - Revista Brasileira de Marketing, São Paulo, v. 10, n. 2, p 126-145, mai./ago. 2011. 
De maneira geral, quando se usa um questionário a ser preenchido pelo respondente sozinho, devem-se preferir as questões fechadas (Aaker, Kumar, \& Day, 2007). O instrumento de pesquisa elaborado teve como base de referência o artigo de Mendes (2008) que, analogamente, analisou a influência do marketing verde na decisão de compra dos estudantes universitários de Fortaleza (CE).

A amostra compôs-se de 100 estudantes dos Cursos de Administração da Faculdade de Ciências Integradas do Pontal da Universidade Federal de Uberlândia - FACIP/UFU e Faculdade Triângulo Mineiro - FTM. O universo populacional compreende aproximadamente 350 alunos, portanto investigou-se $28,6 \%$ da população. A população e amostra pesquisada foram definidas por conveniência das pesquisadoras, visto as duas IES localizaram-se no mesmo município e oferecerem o curso de graduação em Administração, além da facilidade de acesso e rapidez na coleta de dados.

A Faculdade Triângulo Mineiro é uma instituição particular situada no Triângulo Mineiro que oferece os cursos de Administração, Ciências Contábeis e Publicidade e Propaganda. Foi fundada em 1968 com o nome de Escola Superior de Administração de Empresas de Ituiutaba (EAEI), e o curso de Administração foi o primeiro a ser oferecido.

A Faculdade de Ciências Integradas do Pontal (FACIP) foi criada em decorrência do Programa de Apoio ao Plano de Reestruturação e Expansão das Universidades Federais (REUNI), em 2006, e é uma expansão da Universidade Federal de Uberlândia (UFU) com campus em Ituiutaba-MG, no Pontal do Triângulo Mineiro. A FACIP é uma unidade com características muito particulares, visto que desde sua implantação ofertou diversos cursos em áreas distintas de conhecimento, dentre eles os cursos de graduação em Matemática, Administração, Ciências Contábeis, Biologia, Pedagogia, Geografia, História, Física e Química. A partir de 2010 foram criados os cursos de Engenharia de Produção e Serviço Social totalizando, atualmente, a oferta de onze cursos de graduação.

Em razão da não normalidade dos dados, identificada por meio do teste de normalidade, optou-se por análises não paramétricas. Os dados coletados foram tabulados e analisados por meio de análise de frequências e cruzamento de variáveis (crosstabs) usando-se o software estatístico SPSS versão 16.0 .

REMark - Revista Brasileira de Marketing, São Paulo, v. 10, n. 2, p 126-145, mai./ago. 2011. 


\section{RESULTADOS E DISCUSSÕES}

Esta seção apresenta os resultados obtidos com a pesquisa e a discussão desses resultados.

\subsection{ANÁLISE DE FREQUÊNCIA}

Conforme exposto, a pesquisa de campo foi aplicada aos estudantes do curso de Administração de duas IES (UFU e FTM) e os resultados são apresentados a seguir. As respostas obtidas possibilitaram uma análise do perfil dos entrevistados e uma compreensão quanto à percepção dos jovens graduandos em administração relativa à questão ambiental e ao marketing verde, possibilitando, ainda, o conhecimento das ações dos estudantes em relação a este assunto.

Dentre os entrevistados, 58 jovens cursam administração na UFU e 42 na FTM, possuem entre 19 e 25 anos (74\%) e são do sexo feminino (64\%). A renda familiar observada para $41 \%$ dos entrevistados varia entre $\mathrm{R} \$ 2.500,00$ e $\mathrm{R} \$ 5.000,00$ e entre $\mathrm{R} \$ 1.000,00$ e $\mathrm{R} \$ 2.500,00$ para $38 \%$ destes. Constatou-se que $89 \%$ dos estudantes residem na cidade em que estudam e $75 \%$ das famílias dos entrevistados compõem-se de 2 a 5 pessoas.

Quando questionados se possuem alguma preocupação quanto à degradação do meio ambiente, $95 \%$ responderam que sim, entretanto, $61 \%$ destes declararam que comprariam um produto mesmo tendo consciência de que o processo produtivo para a sua fabricação agredisse o meio ambiente. Percebe-se que, na prática, os hábitos de consumo desses jovens distanciam-se do discurso que impera na sociedade, relacionado à necessidade de preservar o meio ambiente e à responsabilidade de cada um neste processo, corroborando a literatura, visto que Smith e Haugtvedt (1995) e Waissman (2001) afirmam que, apesar de a sociedade dizer que está mudando suas atitudes em relação às questões ambientais, na prática ainda há dissonância entre a tendência da intenção e a realidade dos fatos perante o comportamento.

Na questão em que os entrevistados são questionados quanto à importância da prática do marketing verde nas empresas, o contraste também é evidenciado. Assim, dos jovens que reconhecem ser muito importante $(60 \%)$ ou importante $(26 \%)$ a prática do marketing verde nas empresas, $78 \%$ não se importam em saber se o produto que está adquirindo possui algum selo verde, ou seja, se o produto é ecologicamente correto.

Apesar da disparidade evidenciada nas questões que relacionam pensamentos e ações, observa-se uma tendência de mudança, de forma que a maioria dos entrevistados expressou o desejo

REMark - Revista Brasileira de Marketing, São Paulo, v. 10, n. 2, p 126-145, mai./ago. 2011. 
de constituir hábitos mais condizentes com o que julgam ser o correto. Assim, dos $58 \%$ dos jovens que responderam que não comprariam um produto somente por este ser ecologicamente correto, $79 \%$ expressaram o desejo de mudar seus hábitos de compra, aderindo à prática do consumo consciente. As constatações são convergentes às afirmações de Stone, Barnes e Montgomery (1995) de que o consumo consciente reflete conscientização, valores pessoais, além do desejo genuíno de agir de acordo com as questões ambientais.

Relativamente ao marketing verde, $72 \%$ dos entrevistados declararam já ter ouvido falar sobre a questão; $54 \%$ destes tiveram como fonte a universidade e $26 \%$ tomaram conhecimento da temática por meio da internet. Esse fato comprova que, apesar da maioria dos estudantes saber sobre a temática, nem todos tiveram acesso a ela por meio das discussões disciplinares. Constatouse, por meio das afirmações dos respondentes, que nas IES investigadas o curso de graduação em administração não oferece, como conteúdo de natureza obrigatória tampouco optativa, a disciplina relativa a Marketing ou Gestão Ambiental, reafirmando o que preconizam Ribeiro e Miranda (2011) ao enfatizarem que, embora haja uma clara percepção da urgência de implantar disciplinas na área de gestão ambiental nos cursos de administração para formar gestores mais capacitados a lidar com a questão, muitas IES não aderem a essa proposição.

Nota-se que os jovens reconhecem a importância atual das empresas demonstrarem uma preocupação com o meio ambiente, de modo que dentre $95 \%$ daqueles que têm essa percepção, a quase totalidade (98\%), quando futuros administradores de empresas, implementariam a prática do marketing verde.

Uma evidência clara de que os jovens entrevistados reconhecem a importância deste tema, não só como uma preocupação atual, mas também como uma prática importante para seu futuro como gestor, é que $94 \%$ demonstraram o interesse em buscar mais informações e se inteirarem mais sobre o assunto. As afirmações estabelecidas aqui também encontram respaldo na literatura visto que, segundo Ribeiro e Miranda (2011), as discussões sobre a temática deixam claro que é necessário ao administrador conhecer temas relevantes à sua formação, especialmente aqueles relacionados à gestão ambiental, responsabilidade social e sustentabilidade, que o auxiliarão na realização de suas atividades no mercado empresarial.

REMark - Revista Brasileira de Marketing, São Paulo, v. 10, n. 2, p 126-145, mai./ago. 2011. 


\subsection{CRUZAMENTO DE VARIÁVEIS (CROSSTABS)}

O cruzamento das variáveis permite inferências mais precisas sobre a percepção dos universitários a respeito da temática em estudo.

Tabela 1. Percentual de respostas afirmativas às questões sobre o consumo consciente.

\begin{tabular}{|c|c|c|c|c|c|c|c|}
\hline \multirow{2}{*}{ Variáveis de caracterização } & \multicolumn{2}{|c|}{ Sexo } & \multirow{2}{*}{$\begin{array}{c}\text { Idade } \\
\text { Entre 19 e } \\
25 \text { anos } \\
(\%)\end{array}$} & \multicolumn{2}{|c|}{ Renda em R\$ } & \multicolumn{2}{|c|}{$\begin{array}{c}\text { IES em que } \\
\text { estuda }\end{array}$} \\
\hline & $\begin{array}{c}\mathbf{M} \\
(\%)\end{array}$ & $\begin{array}{c}F \\
(\%)\end{array}$ & & $\begin{array}{c}1.000,00 \text { a } \\
2.500,00 \\
(\%)\end{array}$ & $\begin{array}{c}2.500,00 \text { a } \\
5.000,00 \\
(\%)\end{array}$ & $\begin{array}{l}\text { UFU } \\
(\%)\end{array}$ & $\begin{array}{c}\text { FTM } \\
(\%)\end{array}$ \\
\hline $\begin{array}{l}\text { Possui alguma preocupação quanto à } \\
\text { questão da degradação do meio } \\
\text { ambiente? }\end{array}$ & 97,2 & 93,8 & 93,2 & 100,0 & 90,2 & 94,8 & 95,2 \\
\hline $\begin{array}{l}\text { Quando vai fazer compras, você se } \\
\text { importa em saber se o produto que está } \\
\text { adquirindo possui algum selo verde, ou } \\
\text { seja, se o produto é ecologicamente } \\
\text { correto? }\end{array}$ & 30,6 & 23,4 & 25,7 & 21,1 & 34,1 & 17,2 & 38,1 \\
\hline $\begin{array}{l}\text { Se não pratica o consumo consciente, } \\
\text { deseja mudar seus hábitos de compras } \\
\text { aderindo a essa prática? }\end{array}$ & $\mathbf{8 8 , 9}$ & 84,4 & 86,5 & 84,2 & 92,7 & 87,9 & 83,3 \\
\hline $\begin{array}{l}\text { Você daria mais valor a uma empresa } \\
\text { que possuísse uma linha de produtos } \\
\text { ecologicamente corretos, ou que de certa } \\
\text { forma demonstrasse alguma preocupação } \\
\text { em relação ao meio ambiente? }\end{array}$ & 100,0 & 92,2 & 94,6 & 94,7 & 95,1 & 94,8 & 95,2 \\
\hline $\begin{array}{l}\text { Você compraria um produto o qual } \\
\text { necessitasse, mesmo tendo consciência } \\
\text { de que o processo produtivo para a sua } \\
\text { fabricação agride o meio ambiente? }\end{array}$ & 69,4 & 56,3 & 62,2 & 60,5 & 61 & 67,2 & 52,4 \\
\hline $\begin{array}{l}\text { Se, no futuro, você se tornar gestor de } \\
\text { uma empresa, implementará o marketing } \\
\text { verde nesta empresa? }\end{array}$ & 94,4 & 100,0 & 97,3 & 97,4 & 100,0 & 96,6 & 100,0 \\
\hline
\end{tabular}

Fonte: Elaborado pelas autoras a partir dos dados da pesquisa (2010).

O cruzamento das variáveis possibilitou identificar que, independentemente de sexo, idade, renda e IES onde o graduando estuda, a preocupação com a degradação do meio ambiente é alta. Todavia verificou-se que os homens se preocupam um pouco mais que as mulheres e os estudantes com renda entre $\mathrm{R} \$ 1.000,00$ e $\mathrm{R} \$ 2.500,00$ se preocupam mais que os demais.

Quando questionados sobre o fato de a existência do selo verde influenciar em uma compra ocorreu o inverso da situação acima, pois, apesar de todos se preocuparem com a degradação do meio ambiente, não se preocupam em consumir produtos "verdes". No entanto, percebeu-se que, em relação às mulheres, os homens observam mais esta questão, assim como os que possuem maior

REMark - Revista Brasileira de Marketing, São Paulo, v. 10, n. 2, p 126-145, mai./ago. 2011. 
renda, também, observam-na mais em relação àqueles que possuem menor renda. Os estudantes da FTM demonstraram maior preocupação em relação à temática que os universitários da UFU.

Quando questionados se pretendem mudar seus hábitos de consumo, a maioria dos alunos respondeu positivamente. Aqueles respondentes do sexo masculino, que apresentaram maior preocupação com o selo verde em relação às mulheres, também são os que mais querem mudar seus hábitos para aderirem à prática de consumo consciente, mostrando mais uma vez que estão mais preocupados com essa causa que elas.

Quando observada a renda, percebe-se que aqueles com maior poder aquisitivo têm maior vontade em mudar os hábitos do que aqueles com menor renda, e os alunos da UFU possuem preocupação maior que os da FTM no quesito adquirir hábitos mais “amigáveis" à natureza.

Quando questionados se dariam mais importância a uma empresa que possuísse uma linha de produtos ecologicamente corretos, a maioria afirmou que sim, sem muita divergência nas respostas. Apenas os respondentes do sexo masculino dão um pouco mais de importância ao fato quando comparados às mulheres. Contrariamente, considerável percentual dos discentes compraria um produto mesmo sabendo que o processo de fabricação agride o meio ambiente, evidenciando, mais uma vez, a dissonância entre o discurso e a prática, conforme afirmação de Smith e Haugtvedt (1995) e Waissman (2001).

Muito embora os estudantes tenham preocupação com a questão ambiental, suas ações ainda não estão voltadas para a resolução dos problemas ambientais. Nesse caso, ao contrário do que se percebeu quando a questão era consciência e preocupação, as mulheres têm uma atitude mais positiva ("verde") do que os homens em relação à compra de produtos que agridem o meio ambiente, assim como os alunos da UFU em relação aos da FTM. A discussão deixa claro que, teoricamente, homens, alunos da FTM, são mais preocupados, mas, na prática, mulheres, alunas da UFU, são mais conscientes.

Quase a totalidade dos alunos é favorável à implantação do marketing verde caso venham a administrar uma empresa no futuro, e as respondentes do sexo feminino, os alunos com renda acima de R $\$ 2.500,00$ e os alunos da FTM são totalmente favoráveis a essa ação. As afirmações indicam que os estudantes são conscientes de que é necessário o administrador conhecer temas relevantes à sua formação profissional, especialmente aqueles que evidenciem a responsabilidade socioambiental das empresas.

REMark - Revista Brasileira de Marketing, São Paulo, v. 10, n. 2, p 126-145, mai./ago. 2011. 


\section{CONSIDERAÇÕES FINAIS}

O objetivo deste estudo foi analisar se os jovens universitários são influenciados pelo marketing verde das empresas, se reconhecem a importância dessa prática, e se, como futuros administradores, eles buscariam incentivá-las em suas empresas. Observou-se a existência de grande contraste ao longo de todas as respostas dos entrevistados sobre a percepção a respeito da temática com relação ao que efetivamente praticam nas questões relacionadas ao meio ambiente e ao consumo consciente. Tal constatação vem ao encontro das afirmações encontradas na literatura.

É fato a importância global que as questões relacionadas à preservação do meio ambiente estão recebendo atualmente, de forma que esse assunto passa a ser incorporado pelas empresas em suas decisões estratégicas, resultando no crescimento da prática do marketing verde. E essa prática só se sustenta por existir hoje um mercado consumidor em expansão desses produtos e que valoriza essa prática das empresas.

Nota-se que ainda há uma distância muito grande entre o que os jovens pensam e suas verdadeiras ações em relação às questões ambientais. Apesar de reconhecerem a importância do marketing verde nas empresas, a maioria dos entrevistados afirmam não ser influenciados por esta prática, de forma que não possuem hábitos de consumo consciente, porém, atuando como administradores, no futuro, pretendem implantar e incentivar tais práticas. Mostra-se uma dissonância entre o discurso e a prática, o que também é respaldado pela literatura.

Percebe-se que esses jovens não reconheceram, na prática, a importância que suas ações individuais podem ter nesse contexto de preservação do meio ambiente, e o quanto seus hábitos de consumo podem influenciar as empresas a aderirem ao desenvolvimento sustentável.

É fato que o consumidor ecologicamente correto ainda se resume a um pequeno segmento da sociedade, embora esse seleto grupo esteja em crescimento. Por isso, pretende-se chamar a atenção neste estudo para a importância da conscientização do jovem, que tem a oportunidade de impactar positivamente em seu convívio social e em seu futuro ambiente profissional, adotando hábitos de consumo consciente.

Salienta-se, também, a inexistência de exigência da inserção de disciplinas ligadas às questões ambientais nas diretrizes curriculares do curso de graduação em Administração, o que faz com que tal questão fique restrita a discussões extracurriculares e a critério do colegiado ou coordenadores de curso.

REMark - Revista Brasileira de Marketing, São Paulo, v. 10, n. 2, p 126-145, mai./ago. 2011. 
A questão é que as mudanças requeridas não podem ser mais adiadas, estas devem consistir em um plano de ação imediato. O discurso em relação à preservação do meio ambiente deve parar de ser somente repetido pelos cidadãos e colocado em prática, pois esta é a única forma de observarem-se resultados concretos relativos a questões ambientais e de sustentabilidade.

\section{REFERÊNCIAS}

Aaker, A. D., Kumar, V., \& Day, G. S. (2007). Pesquisa de marketing (2a ed.) São Paulo: Atlas.

Barbiere, J. C. (2007). Gestão ambiental empresarial: conceitos, modelos e instrumentos. (2a ed.) São Paulo: Saraiva.

Butzke, I. C., Pereira, G. R., \& Noebauer, D. (2002). Sugestão de indicadores para avaliação do desempenho das atividades educativas do sistema de gestão ambiental - SGA da Universidade Regional de Blumenau. Revista Eletrônica do Mestrado em Educação Ambiental, 13. Recuperado em 20 julho, 2011, de http://www.fisica.furg.br/mea/remea/congress/artigos/comunicacao13.pdf

Cascino, F. (2000). Educação ambiental: princípios, histórias e formação de professores. São Paulo: SENAC.

Chamorro, A., \& Bañegil, T. M. (2006). Green marketing philosophy: a study of spanish firms with ecolabels. Corporate Social Responsibility and Environmental Management, 13(1), 11-24.

Charter, M. (1992). Greener Marketing: A Responsible Approach to Business. Sheffield, UK: Greenleaf. Publishing.

D'avignon, A. (1996). Normas ambientais ISO 14000: como podem influenciar sua empresa. Rio de Janeiro: CNI, DAMPI.

Dias, G. F. (2006). Educação ambiental: princípios e práticas. (9a ed.). São Paulo: Gaia.

Donaire, D. (1994). Considerações sobre a influência da variável ambiental na empresa. Revista de Administração de Empresas, 34(2), 68-77.

REMark - Revista Brasileira de Marketing, São Paulo, v. 10, n. 2, p 126-145, mai./ago. 2011. 
Donaire, D. (1999). Gestão ambiental na empresa. (2a ed.). São Paulo: Atlas.

Eco \& Ação (2010). Ecologia e responsabilidade: relatório nosso futuro comum. Recuperado em 28 abril, 2008 de http://www.ecoeacao.com.br/index2.php?option=com_content\&do_pdf=1\&id=5040

Ferreira, D. D. M, \& Ferreira, L. F. (2008, agosto). O ensino de gestão ambiental nos cursos de administração de empresas nas IES (Instituições de Ensino Superior) do Estado de Santa Catarina: um estudo exploratório. Anais do Congresso Nacional de Excelência em Gestão, Niterói, RJ, Brasil, 5.

Ferrel, O. C., \& Pride, W. M. (2001). Marketing: conceitos e estratégias. Rio de Janeiro: LTC.

García, M. S. A., Aldamiz-Echevarría, C., Durana, G., Abando, J. C., \& Molina, A. V. (2003, janeiro-fevereiro). El consumidor ecológico: un modelo de comportamiento a partir de la recopilación y análisis de la evidencia empírica. Distribución y Consumo, 67(4), 1-53.

Gobe, A. C, Moreira, J. C., Perez, M. C., Carramenha, P. R., \& Pasquale, P. (2004). Gerência de produtos. São Paulo: Saraiva.

Haour, G. (1999). Questões ecológicas: ameaça ou oportunidade? São Paulo: Makron.

Instituto AKATU. (2009). Consumo ecologicamente correto. Recuperado em 28 abril, 2010 de http://www.akatu.org.br.

Kotler, P. (1999). Marketing para o século XXI: como criar, conquistar e dominar mercados. São Paulo: Futura.

Kotler, P., \& Keller, K. L. (2006). Administração de marketing. (12a ed.). São Paulo: Prentice Hall.

Lei $n^{o}$ 9.795, de 27 de abril de 1999 (1999). Dispõe sobre a Política Nacional de Educação Ambiental e dá outras providências. Diário Oficial [da] República Federativa do Brasil. Brasília, DF, 28 de abril de 1999. Recuperado em 26 abril, 2010 de http://www.planalto.gov.br

Limeira, T. M. V. (2008). Comportamento do consumidor brasileiro. São Paulo: Saraiva.

REMark - Revista Brasileira de Marketing, São Paulo, v. 10, n. 2, p 126-145, mai./ago. 2011. 
Mattar, F. N. (1996). Pesquisa de marketing. São Paulo: Atlas.

Mendes, I. S. Consumo Consciente: a influência do marketing verde na decisão de compra dos estudantes universitários de Fortaleza/CE. Recuperado em 15 abril, 2010 de http://www.ethos.org.br/_Uniethos/Documents/CONSUMO\%20CONSCIENTE\%20\%20A\%20INFLU\%C3\%8ANCIA\%20DO\%20MARKETING\%20VERDE\%20NA\%20DECI S\%C3\%830\%20DE\%20COMPRA\%20DOS\%20ESTUDANTES\%20UNIVERSIT\%C3\%81 RIOS\%20DE\%20FORTALEZA_CE. pdf.

Menon, Anil, Menon, Ajay, Chowdhury, J., \& Jankovich, J. (1999). Evolving paradigm for environmental sensitivity in marketing programs: a synthesis of theory and practice. Journal of Marketing Theory and Practice (Spring), 7(2), 1-15.

Mintu-Wimsatt, A. T., \& Bradford, D. M. (1995). In search of market segments for green products. In: Polonsky, M. J. \& Mintu-Wimsatt, A. T. (Eds.). Environmental marketing: strategies, practice, theory and research. Nova Iorque: Haworth.

Motta, S. L. S. (2007). Motivações para o lançamento de um produto ecologicamente correto: um estudo de caso. Revista de Gestão USP, 14(1), 31-40.

Motta, S. L. S., \& Rossi, G. B. (2003). A influência do fator ecológico na decisão de compra de bens de conveniência: um estudo exploratório na cidade de São Paulo. Revista de Administração, 38(1), 46-57.

Mowen, J. C., \& Minor, M. S. (2003). Comportamento do consumidor. São Paulo: Pearson Prentice Hall.

Ottman, J. A. (1994). Marketing verde: desafios e oportunidades para a nova era do marketing. São Paulo: Makron Books.

Ottman, J. A. (1998). Green marketing: opportunity for innovation. Chicago, IL: NTC Business Books.

Peattie, K. (1995). Environmental marketing management: meeting the green challenge. London: Pitman Publishing.

REMark - Revista Brasileira de Marketing, São Paulo, v. 10, n. 2, p 126-145, mai./ago. 2011. 
Peattie, K. (1999). Rethinking marketing. In M. Charter \& J. M. Polonsky (Eds.). Greener marketing: a global perspective on greening marketing practice. (pp. 57-70). Sheffield, UK: Greenleaf Publishing.

Polonky, M. J. (1994). Green marketing regulation in the US and Australia: the australian checklist. Green Management International.

Polonsky, M. J., \& Rosenberger, P .J. (2001). Reevaluating green marketing: a strategic approach. Business Horizons, 44(5), 21-30.

Pombo, F. R., \& Magrini, A. (2008). Panorama de aplicação da norma ISO 14001 no Brasil. Revista Gestão \& Produção, 15(1), 1-10.

Ribeiro, K. M. B., \& Miranda, A. C. (2011, janeiro-abril). Matriz Curricular do curso de Administração: qual a relevância da temática ambiental na formação do Administrador? Revista UNIABEU, 4(6).

Roxo, C. A. (1996). Case Studies. Revista Brasileira de Management. Rio de Janeiro: InSight Engenharia de Comunicação e Marketing.

Silva, A. A. (2001). Gestão ambiental e competitividade: um estudo de caso na Companhia Brasileira de Amarras - BRASILAMARRAS. Anais do Encontro Anual da Associação Nacional dos Programas de Pós-Graduação e Pesquisa em Administração, Campinas, SP, Brasil, 25.

Smith, S., \& Haugtvedt, C. P. (1995). Environmental marketing: strategies, practice, theory and Research. NewYork.

Starke, L. (1991). Lutando por nosso futuro comum. Rio de Janeiro: FGV.

Stone, G., Barnes, J. H., \& Montgomery, C. (1995). Ecoscale: a scale for the measurement of environmentally responsible consumers. Psychology \& Marketing, 12, 595-612.

Tse, A. C. B., \& Yim, F. H. K. (2002). How do consumers perceive clear and transparent products? International Journal of Commerce \& Management, 12(1), 68-78.

REMark - Revista Brasileira de Marketing, São Paulo, v. 10, n. 2, p 126-145, mai./ago. 2011. 
Waissman, V. (2001). Como o marketing verde interfere na imagem de marca da indústria de celulose: o estudo de caso da Aracruz Celulose S.A. Dissertação de mestrado, Fundação Getúlio Vargas, São Paulo, SP, Brasil.

Wasik, J. (1996). Green marketing and management: a global perspective. Cambridge, MA: Blackwell.

Welford, R. (1995). Environmental strategy and sustainable development: the corporate challenge for the 21 st century. London: Routledge.

WWF Brasil. (2010). Desenvolvimento sustentável. Recuperado em 28 abril, 2010 de http://www.wwf.org.br

\title{
THE INFLUENCE OF GREEN MARKETING IN CONSUMPTION HABITS OF YOUNG UNIVERSITY COURSE MANAGEMENT: A STUDY IN INSTITUTIONS OF HIGHER EDUCATION (IES)
}

\begin{abstract}
Negative impact from industrial and market activities and supporters of capitalist societies are explicit in bringing environmental consequences such as pollution, waste accumulation and the destruction of fauna and flora.. An increasing number of people realize they take an active part in the process of environmental destruction and that their actions can either contribute to worsen as well as to improve the situation. The objective of this study is to analyze the influence of green marketing in consumer habits of students from two HEIS in the interior of Minas Gerais and whether they recognize the importance of this practice and as future managers, would seek to encourage them in their businesses. We conducted a literature search to conceptualize the themes: green marketing, consumer behavior and consumer awareness. The research instrument was a questionnaire. The collected data were analyzed using SPSS software. The study made it possible to infer that there is a huge gap between what young people think and their real actions in relation to environmental issues. Despite that those interviewed recognized the importance of green marketing in business, most states are not influenced by this practice so do not have conscious consumer habits.
\end{abstract}

Key-Words: Marketing; green marketing; consumption habits; graduates in administration.

REMark - Revista Brasileira de Marketing, São Paulo, v. 10, n. 2, p 126-145, mai./ago. 2011. 
Data do recebimento do artigo: 23/03/2011

Data do aceite de publicação: 02/07/2011

REMark - Revista Brasileira de Marketing, São Paulo, v. 10, n. 2, p 126-145, mai./ago. 2011. 